\author{
수직 원형관내 혼합대류 유동영역지도의 유효성 검토 \\ 강경욱 ${ }^{*}$. 김형진 ${ }^{*}$. 윤시태* · 정범진 ${ }^{* * \dagger}$ \\ *한국원자력환경공단 기술연구소, ${ }^{* *}$ 경희대학교 원자력공학과 \\ (2014년 4월 15일 접수, 2014년 9월 15일 수정, 2014년 9월 17일 채택)
}

\title{
Validity Review of Mixed Convection Flow Regime Map in Vertical Cylinders
}

\author{
Gyeong-Uk Kang ${ }^{*} \cdot$ Hyoung-Jin Kim ${ }^{*} \cdot$ Si-Tae Yoon ${ }^{*} \cdot$ Bum-Jin Chung ${ }^{* * \dagger}$ \\ *Research \& Development Institute, Korea Radioactive Waste Agency \\ ${ }^{* *}$ Department of Nuclear Engineering, Kyung Hee University
}

(Received 15 April 2014, Revised 15 September 2014, Accepted 17 September 2014)

\section{요약}

본 연구에서는 기존에 알려진 수직 원형관내 혼합대류 유동영역지도에 대하여 원 문헌의 분석과 재구성을 통해 지도의 유효성 검토를 수행하였다. 지도를 구성하는 원 문헌을 수집하여 내용을 정리하 였고 조사한 데이터와 대류열전달 상관식을 활용하여 독립적으로 지도를 재구성하고 기존의 지도와 비교하였다. 재구성한 지도에는 혼합대류 영역이 곡선이 아니라 직선으로 나타났으며 천이영역을 나 타내는 것은 재현되지 않았다. 일부 데이터만 포함된 기존의 지도와 달리 재구성 지도에는 상당히 많은 양의 데이터가 포함됐다. 기존의 유동영역지도는 활용된 데이터가 선택적으로 사용되었고, 혼합 대류와 천이영역을 나타내는 실선 대해 언급되지 않았으며 불확실도 분석을 통한 정보를 제공하지 않았기 때문에 신뢰할 수 없다고 판단된다. Metais와 Eckert의 연구 이후, 혼합대류에 관한 많은 연구 가 수행되었으나 대류의 유동영역을 구분하는 방법으로 기존의 지도가 지금까지 활용되고 있다.

주요어 : 순부력유동, 수직 원형관, 역부력유동, 유동영역지도, 혼합대류

\begin{abstract}
The existing flow regime map on mixed convection in vertical cylinders was investigated through an analysis of original literatures and its re-formation. The original literatures related to the existing map were reviewed. Using the investigated data and heat transfer correlations, the map was redrawn independently, and compared with the existing map. The redrawn map showed that mixed convection regime was not curved lines but straight lines and the transition regime was unable to be reproduced. Unlike the existing map with a little data, there are lots of data in the redrawn map. The reviews revealed that the existing map used the data selectively among the experimental and theoretical results, and a detailed description for lines forming mixed convection and transition regime was not provided. While considerable studies on mixed convection have been performed since that of Metais and Eckert, the existing map has still been used as the best method to distinguish natural, forced and mixed convection regime.
\end{abstract}

Key words : Buoyancy-aided flow, Buoynacy-opposed flow, Flow Regime Map, Vertical Cylinder, Mixed Convection

\footnotetext{
${ }^{\dagger}$ To whom corresponding should be addressed.

Department of Nuclear Engineering, Kyung Hee University

Tel : 031-201-3893 E-mail : bjchung@khu.ac.kr
} 
강경욱 · 김형진 · 윤시태 · 정범진

\section{1. 서 론}

대류열전달 환경에서 혼합대류(Mixed convection) 는 자연대류(Natural convection)와 강제대류(Forced convection)의 구동력(Driving force)이 유사할 때 발 생한다 ${ }^{(1 \sim 2)}$. 자연대류는 항상 중력과 반대방향으로 작용하지만 강제대류의 방향은 임의적이다. 수직 원 형관 내부를 흐르는 유동의 경우, 강제대류의 방향이 부력의 방향과 같은 상방향의 유동을 순부력 유동 (Buoyancy-aided flow)이라 하며, 반대로 강제대류의 방향이 부력과 방향이 다른 하방향의 유동을 역부력 유동(Buoyancy-opposed flow)이라고 한다.

층류 혼합대류의 경우, 순부력 유동은 강제대류의 방향이 부력과 같기 때문에 유속을 증가시켜 동일한 Reynolds 수를 가지는 강제대류에 비해 열전달이 향 상되며 역부력 유동에서는 오히려 유속이 감속되어 열전달이 감소한다. 그러나 난류 혼합대류가 되면, 층 류와는 반대로 역부력 유동에서 열전달이 강제대류보 다 향상되고 순부력 유동에서는 낮은 부력계수 (Buoyancy coefficient)에서 강제대류보다 열전달이 적다가 부력계수가 증가하면 다시 열전달이 회복된 다. 이것은 난류생산(Turbulence production)과 관련 되었기 때문이다 ${ }^{(3)}$.

대류의 종류는 유동의 영역지도(Flow regime map) 를 통하여 단순한 형태로 나타낼 수 있다. Fig. 1은 수직 원형관 내부의 유동에 대해 Metais와 Eckert ${ }^{(4)}$ 가 제시한 유동영역지도로 Grashof 수와 Reynolds 수에 따른 유동의 양상을 구분한 것이다. 이는 혼합 대류에 관하여 가장 정통적인 연구로 알려져 있고 자 주 인용되며 여러 연구자들의 실험적, 이론적 연구결 과들이 Metais와 Eckert에 의해 정리된 것으로써 현 재까지도 유동영역을 구분하는 방법으로 널리 이용되 고 있다. Fig. 1 을 살며보면, 가로축은 자연대류의 무 차원수인 Grashof 수에 Prandtl 수와 관의 지름과 길 이의 비 $\left(\mathrm{D}_{\mathrm{i}} / \mathrm{L}\right)$ 가 곱해진 형태의 무차원수이며 세로축 은 강제대류의 무차원수인 Reynolds 수이다. 두 개의 곡선으로 둘러싸인 부분이 강제대류와 자연대류의 구 동력이 비슷한 혼합대류 영역이며 왼쪽 하단은 층류 혼합대류, 오른쪽 상단은 난류 혼합대류 영역이다. 이 영역에서 Reynolds 수가 증가하거나 Grashof 수가 감소하면 강제대류가 되며, 반대로 Reynolds 수가 감 소하거나 Grashof 수가 증가하면 자연대류가 된다. 이러한 유동영역지도안에는 총 9 명의 연구자들의 연

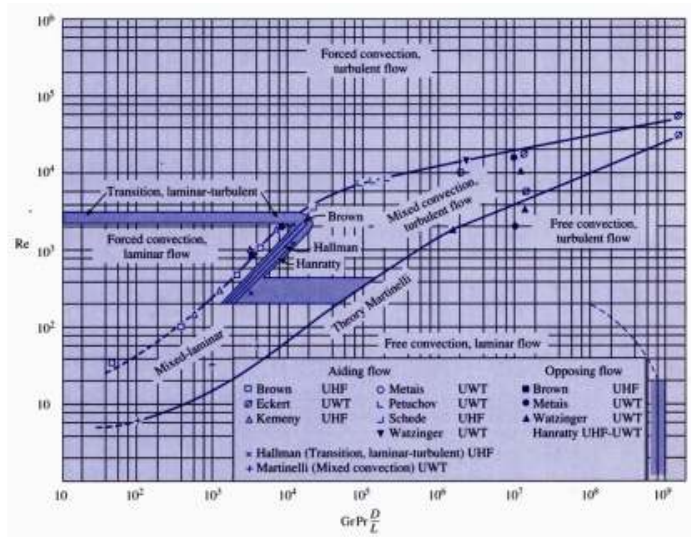

Fig. 1. Classical flow regime map on mixed convection in vertical cylinders.

구결과가 포함되어 있다.

Metais와 Eckert의 논문을 조사한 바에 따르면, 어 떠한 방법에 의해 지도가 만들어졌는지에 대한 구체 적인 설명은 나와 있지 않고 다만, 지도의 축에 대한 설명, 무차원수의 특성길이(Characteristic length)가 관의 직경 $\left(\mathrm{D}_{\mathrm{i}}\right)$ 인 것 등의 개략적인 설명이 전부이다.

본 연구는 문헌조사를 통해 기존 유동영역지도의 유효성에 대해 검토를 하였다. 지도를 구성하고 있는 원 문헌을 수집하였으며 연도별로 순서대로 분석하여 정리하였다. 이러한 과정을 통하여 조사된 열전달 상 관식과 데이터를 활용하여 독립적으로 지도를 재구성 하였으며 기존의 유동영역지도와 유사한 형태의 그림 이 그려지는지 확인 및 비교분석 하였다.

\section{2. 기존 문헌분석}

\section{2-1. Watzinger와 Johnson ${ }^{(5)}$ 의 연구}

난류 혼합대류 연구는 1939년 Watzinger와 Johnson에 의해 처음으로 시도되었다. 그들은 관의 길이와 지름의 비 $\left(\mathrm{H} / \mathrm{D}_{\mathrm{i}}\right)$ 가 20 인 원형관을 사용하여 관의 내벽이 차갑게 유지될 때, 따뜻한 물을 관의 위, 아래로 흘려주는 방식으로 순부력 유동과 역부력 유 동에 대해 실험하였다. 열전달계수를 측정하는데 필 요한 물성치들을 구하기 위하여 벽면과 물 온도 사이 의 평균인 막온도(Film temperature)를 사용하였고 막온도에 따라 Prandtl 수는 같은 물에 대해서도 2 5 의 범위에서 값이 변하였다. 연구범위는 Grashof 수 가 $6 \times 10^{6} \sim 10^{8}$ 이고 Reynolds 수는 1,450 15,000으 로 Fig. 1 에 의하면 충분히 난류 혼합대류 영역에 해 


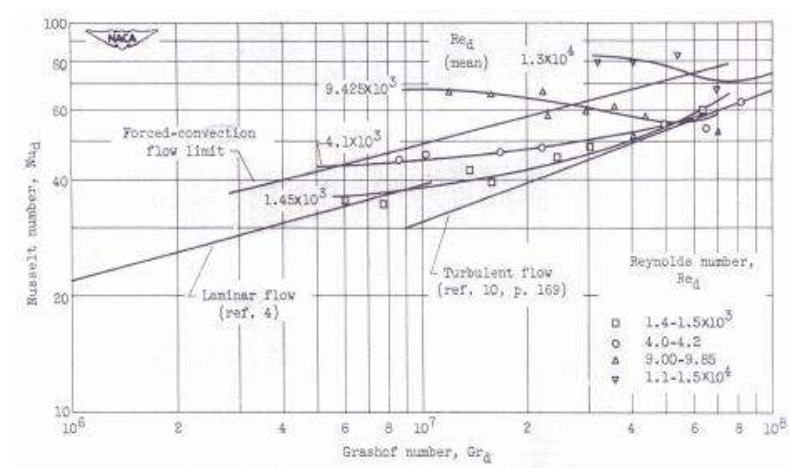

Fig. 2. Classical flow regime map on mixed convection in vertical cylinders.

당한다. 무차원수의 특성 길이척도로 관의 지름을 사 용하였다. Fig. 2는 실험한 결과이며 여러 가지의 Reynolds 수에 대하여 Grashof 수에 대한 Nusselt 수 를 보여준다. 이것은 Eckert 등이 재구성하여 나타낸 것으로 그들의 문헌에서 발췌한 것이다. Watzinger와 Johnson의 문헌에서는 온도와 속도 그리고 벽면의 길이에 따른 속도 등을 보여주는 그래프만이 제시되 어 유동영역에 대한 정보를 제공하지 않았다. 그래서 Eckert 등은 그들의 실험결과와 비교하고 유동영역에 대한 정보를 얻고자 Watzinger와 Johnson의 실험값 을 활용하여 Fig. 2와 같이 재구성하여 나타내었다. 사각형, 원형 및 삼각형의 점들은 Reynolds 수가 일 정한 실험결과이며 곡선들은 이들을 Fitting한 것이 다.

Forced convection flow limit으로 표기된 위의 실 선은 강제대류와 혼합대류 영역의 경계지점을 나타낸 다. 아래의 실선은 층류와 난류의 자연대류 열전달상 관식이다. 오른쪽 상단의 두 곡선은 Grashof 수가 감 소하여 실선을 벗어날 때 Nusselt 수의 값이 거의 일 정하다. 그 이유는 이 영역이 강제대류에 해당되므로 Nusselt 수는 자연대류의 영향에 무관해지기 때문이 다. 그러나 Grashof 수가 증가하면 우측 하단으로 휘 어지다가 난류 자연대류의 상관식에 수렴하는 경향을 보인다. 따라서 두 개의 실선 사이의 영역 즉, Forced convection limit와 자연대류 상관식의 사이를 혼합대 류 영역이라 직관적으로 판단할 수 있다.

한편, 역부력 유동에 대해서는 몇 가지 정도의 실

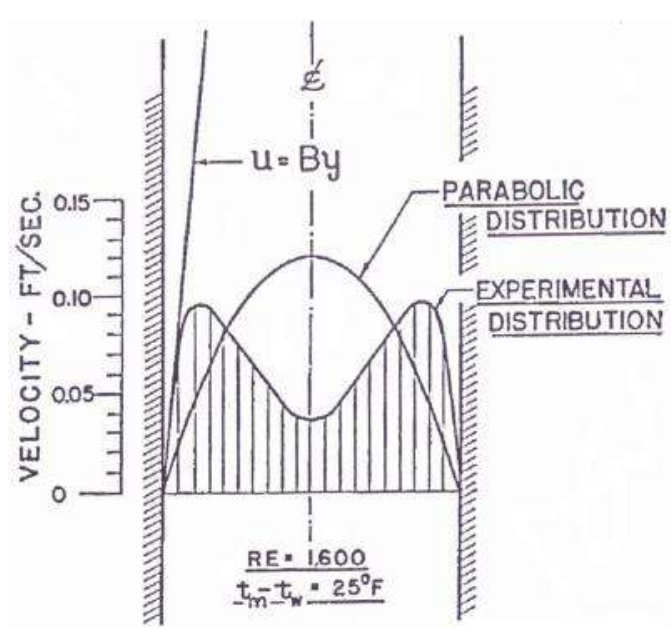

Fig. 3. Comparison of the velocity distribution observed by Watzinger \& Johnson and the ideal parabolic distribution.

험만이 수행되었고 실험결과는 순부력 유동에서의 열 전달계수와 비교되었다. 비교결과 역부력 유동의 열 전달계수가 순부력 유동의 그것보다 약 6 20 퍼센 트 정도의 높게 측정됨을 보인 반면에 측정된 현상에 대해서는 언급하지 않았다.

\section{2-2. Martinelli와 Boelter ${ }^{(6)}$ 의 연구}

Martinelli와 Boelter는 1942년에 수직평판에서 층 류 혼합대류 순부력 유동에 대해 수치해석을 수행하 여 열전달상관식을 제시하였다. 그들은 열전달상관식 을 유도하는데 세 가지 근사법을 적용하였다. 우선, 무한대의 길이로 마주보는 두 개의 가열벽(Heated wall)에 대해 열전달문제를 이론적으로 해석하였다. 첫 번째 근사법에서는 자연대류의 영향을 고려하지 않고 온도에 따른 밀도변화가 일정하다고 가정하였 다. 따라서 가열벽과 인접한 유체의 속도는 거의 선 형적인 분포에 가까웠으며 포물선의 형태를 띠었다. 즉, 열전달은 가열벽과 인접한 유체에 대해서만 이루 어지며 중심부에 대해서는 고려되지 않았다. 그러나 Watzinger와 Johnson은 실험적 연구를 통하여 관내 의 속도분포가 Fig. 3 에서 보는 바와 같이 자연대류 의 영향으로 포물선의 형태가 아닌 벽면근처에서는 선형적인 모습을 보이다가 중심부로 갈수록 감소하는 모습이 나타남을 발견하였다.

Martinelli와 Boelter는 속도분포가 포물선 형태라 고 다시 가정하여 첫 번째 근사법에서 사용한 것과 같은 기하구조에 대해 두 번째 근사법을 제시하였다. 
온도에 따른 밀도의 변화가 추가되어 자연대류의 영 향이 고려되었고 동일한 조건에서 관의 길이와 지름 의 비 $\left(\mathrm{L} / \mathrm{D}_{\mathrm{i}}\right)$ 가 큰 원형관에 대하여 세 번째 근사법을 제시하였다. 위의 세 가지 근사법은 유체가 가열벽으 로 직접 들어오는 것이 아닌 단열벽(Adiabatic wall) 을 통하여 들어오기 때문에 유체속도는 가열벽 입구 서부터 완전발달유동(Fully-developed flow)이라 가 정되었다.

세 가지의 근사법에 따른 열전달상관식이 제시되 어 있지만, 자연대류의 영향을 고려한 두 번째와 세 번째 근사법으로부터 도출한 열전달상관식만을 나타 내었다. 두 번째 근사법인 두 개의 수직평판에서의 혼합대류 열전달상관식은 식 (1)과 같다. 식 (1)을 원 형관의 길이와 지름의 비가 작은 원형관에 적용하면 식 (2)처럼 상수만 바뀌어 표현된다. 이러한 차이는 수직평판의 유동과 원형관내 유동에 대한 평균속도와 최대속도 간의 차이로부터 생겨난다.

$$
\begin{aligned}
& N u_{D}=1.59 \sqrt[3]{G z_{D}+0.096\left(G r_{D} \operatorname{Pr} \frac{D}{L}\right)^{0.75}} \\
& N u_{D}=1.75 \sqrt[3]{G z_{D}+0.0722\left(G r_{D} \operatorname{Pr} \frac{D}{L}\right)^{0.75}}
\end{aligned}
$$

식 (3)은 세 번째 근사법인 길이와 지름의 비가 큰 원통형의 수직관 유동에 대한 혼합대류 열전달상관식 이다.

$$
N u_{D}=1.75 F_{1} \sqrt[3]{G z_{D}+0.0722 F_{2}\left(G r_{D} \operatorname{Pr} \frac{D}{L}\right)^{0.75}}
$$

식 (2)와 (3)은 같은 형태를 취하지만 원형관의 길 이와 지름의 비가 크거나 작은지에 따라서 다르게 적 용된다. 그러나 Martinelli와 Boelter의 연구에서는 어 떤 기준에 의해 식 (2)와 (3)이 구분되어 사용되는지 에 대해서는 구체적으로 조건을 언급하지 않았다.

\section{2-3. Eckert 등()의 연구}

Eckert 등은 1953년에 난류 혼합대류의 순부력 유 동과 역부력 유동에 대하여 국부 열전달계수 측정하 였고 유동의 영역을 결정하는 방법을 제시하였다. Watzinger와 Johnson 그리고 Martinelli와 Boelter의 연구결과와 그들의 연구결과를 포함하여 잠정적인 유

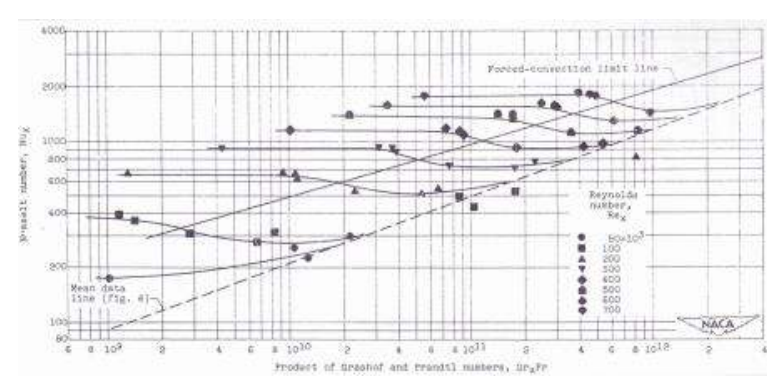

Fig. 4. Dimensionless correlation of local mixed, free and forced convection heat transfer coefficients for buoyancy-aided flow.

동영역지도를 나타내었다. 실험은 공기를 사용하였고 관의 길이에 대한 지름의 비 $\left(\mathrm{H} / \mathrm{D}_{\mathrm{i}}\right)$ 가 5 인 원형관에 대해 Grashof 수 $10^{9} \sim 10^{13}$ 과 Reynolds 수 $36 \times 10^{3} \sim$ $37.7 \times 10^{4}$ 의 범위에서 수행하였다. 가열벽의 입구에서 부터 측정하고자 하는 부분까지의 거리 $\mathrm{x}$ 를 길이척도 로 정의하였다. Fig. 4는 순부력 유동 조건에서 일정 한 Reynolds 수에 대해 $\mathrm{Gr}_{x} \mathrm{Pr}$ 수에 따른 국부 Nusselt 수를 보여준다. Watzinger와 Johnson의 결과 인 Fig. 2와 유사한 형태의 모습을 보였다. 동일한 Reynolds 수에 대하여 측정된 Nusselt 수를 연결한 곡선을 따라가다 보면 Forced convection limit 왼쪽 에서는 $\mathrm{Gr}_{\mathrm{X}} \mathrm{Pr}$ 수의 영향을 받지 않고 일정함을 알 수 있다. 즉, 이 영역은 강제대류에 해당한다. 반면 $\mathrm{Gr}_{\mathrm{x}} \mathrm{Pr}$ 수가 증가하면서 약간 감소하다가 다시 증가하 며 Mean data line을 따라가는 것을 볼 수 있다. 즉, Forced convection limit line과 Mean data line의 사 이가 혼합대류에 해당한다고 다소 직관적으로 말할 수 있다.

이러한 유동영역간의 경계를 결정하는데 있어서 다소 임의적인 방법을 제시하였다. 일반적으로 강제 대류의 영역을 결정할 경우에는 자연대류의 영향이 열전달계수를 $10 \%$ 이내로 변화시키는 지점으로 정의 되며 이것은 자연대류의 영역을 결정할 경우에도 동 일하게 적용된다. Eckert 등은 Fig. 4 의 유동영역을 구분하는 방법을 다음의 식으로 표현하였다. 여기서, 식 (4)는 강제대류와 혼합대류의 영역을 구분하며 식 (5)는 자연대류와 혼합대류의 영역을 구분한다.

Between Forced and Mixed flow

$R e_{x}=15.0\left(G r_{x} \operatorname{Pr}\right)^{0.40}$

Between Natural and Mixed flow 


$$
R e_{x}=8.25\left(G r_{x} \operatorname{Pr}\right)^{0.40}
$$

역부력 유동의 경우에 대해서는 자연대류와 혼합 대류의 영역을 구분하는 식 (6)만을 제시하였다.

\section{Between Naturel and Mixed flow}

$$
R e_{x}=18.15\left(G r_{x} \operatorname{Pr}\right)^{0.33}
$$

\section{2-4. Hanratty 등 ${ }^{(8)}$ 의 연구}

Hanratty 등은 1958년에 일정한 Reynolds 수에 대 해 Grashof 수를 증가시키면서 관내 유동의 속도분포 가 변하는 경향을 관찰하였고 자연대류의 영향이 난 류 혼합대류로의 천이에 미치는 영향을 연구하여 유 동이 불안정해지기 시작하는 지점을 발견하였다. 실 험은 유동이 완전히 발달하는데 충분한 길이와 지름 의 비가 114.3 인 원형관을 사용하였다. Grashof 수는 $3 \times 10^{3} \sim 10^{4}$ 그리고 Reynolds 수는 40 350의 층류 범위에서 수행되었다. Fig. 5의 (a)와 (b)는 순부력 유 동과 역부력 유동에서 자연대류의 증가가 속도분포에 미치는 영향을 보여준다. Fig. 5의 (a)에서 $\mathrm{Gr} / \mathrm{Re}$ 수 가 0 일 때 중심부에서의 속도는 최대가 되며 벽면근 처에서는 최소가 된다. $\mathrm{Gr} / \mathrm{Re}$ 수가 22로 증가하면서 즉, 자연대류에 의하여 속도는 중심부에서 어느 정도 떨어진 곳까지 일정해지다가 벽면근처로 갈수록 단조 증가하게 된다. 자연대류가 매우 커져서 $\mathrm{Gr} / \mathrm{Re}$ 수가 121.6 이 되면 벽면의 속도가 중심부의 속도를 크게 앞지르는 것을 볼 수 있다. 이는 $\mathrm{Gr} / \mathrm{Re}$ 수가 증가하 면 벽면 근처의 유체가 데워지고 부력을 받기 때문에
벽면근처에서의 속도가 달라지기 때문이다. 역부력 유동인 그림 5의 (b)의 경우 자연대류가 커지면 속도 는 중심부에서 높아지며 가열벽면에서는 감소하는 경 향을 보인다.

\section{2-5. Hallman ${ }^{(9)}$ 의 연구}

Hallman은 1961년에 난류 혼합대류로의 천이가 발생하는 지점과 유동이 완전히 발달하는데 필요한 입구길이(Entrance length)를 조사하였다. 관의 지름 과 길이의 비가 115 인 원형관을 사용하여 Grashof 수 $10^{4} \sim 4.5 \times 10^{6}$ 그리고 Reynolds 수 $140 \sim 4,300$ 의 범위에서 수행하였다. 순부력 유동에서 난류로의 천 이를 확인하였으며 Fig. 6은 실험한 결과이며, 선은 Rayleigh 수와 $\operatorname{RePr} /\left(2 \mathrm{x} / \mathrm{D}_{\mathrm{i}}\right)$ 수가 어느 특정한 값을 나타낼 경우에 난류로 천이되는 지점을 나타낸다.

천이를 나타내는 점선은 다음과 같은 식으로 표현 된다.

$$
R a_{D}=9470\left(\frac{R e P r}{2 x / D}\right)^{1.83}
$$

여기서, 가열벽의 입구서부터 천이가 발생하기 시 작하는 지점의 $\mathrm{x} / \mathrm{D}_{\mathrm{i}}$ 는 정확히 측정되지 않았다. 왜냐 하면 가열벽면에 부착된 열전대가 $0.05 \mathrm{~m}$ 간격으로 설 치되어 정확한 위치 파악이 어려웠기 때문이다. 역부 력 유동의 경우에서는 유동이 빈번하게 불안정해지는 현상으로 인하여 난류로의 천이지점에 대한 결과는 제시하지 않았다.

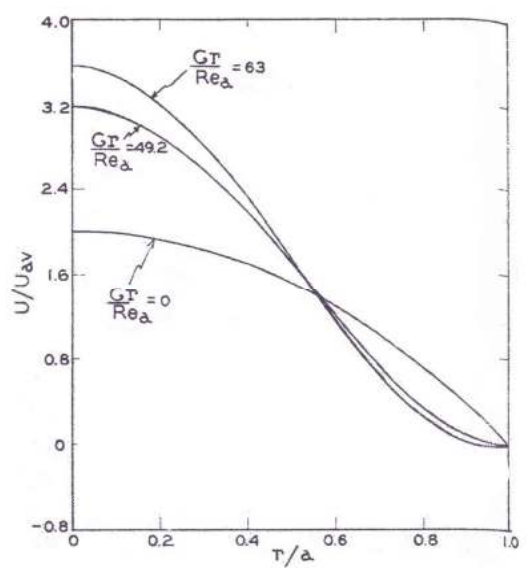

(b) Buoyancy-opposed flow (a) Buoyancy-aided flow

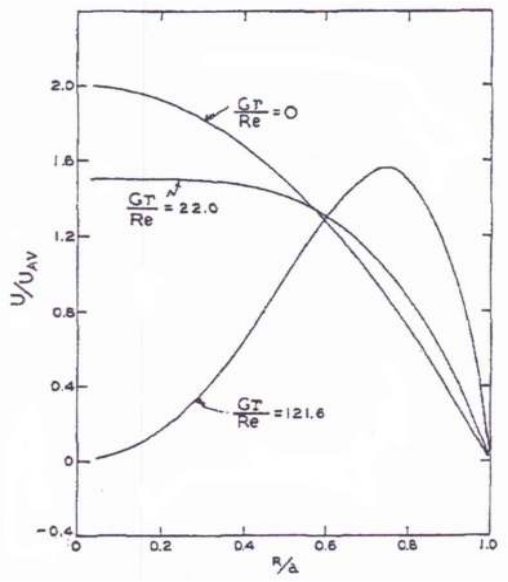

Fig. 5. Velocity profiles inside a vertical pipe for constant heat flux. 


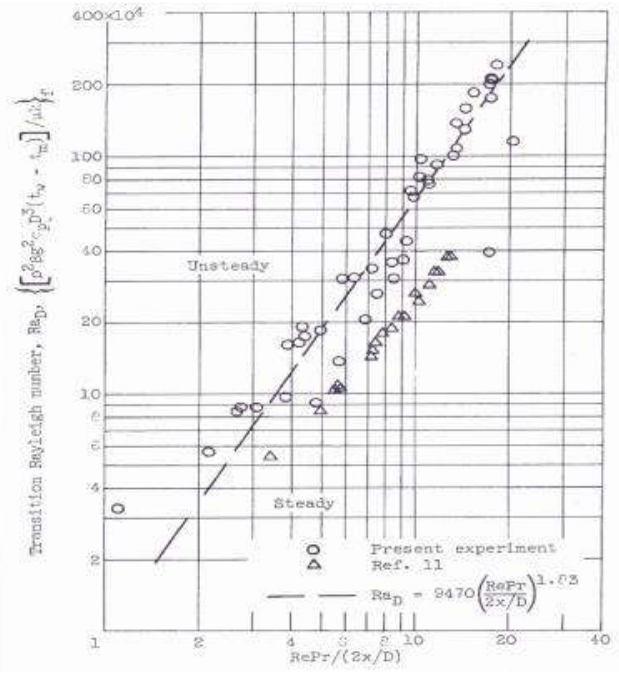

Fig. 6. Correlation of data for transition in buoyancy-aided flow.

\section{2-6. Keminy와 Somers ${ }^{(10)}$ 의 연구}

Kemeny와 Somers는 1962년에 $\mathrm{Gr} / \mathrm{Re}$ 수의 비를 증가시키면서 열전달계수를 측정하였다. 관의 길이는 일정하지만 지름이 다른 네 가지의 관을 사용하여 원 형관의 길이에 대한 지름의 비를 9.7 320로 변화시 켰고 Grashof 수가 $10^{2} \sim 10^{5}$ 범위에서 Prandtl 수 3 $\sim 6$ 의 물과 80 170의 기름을 사용하였다. Reynolds 수는 물의 경우 $61 \sim 6,800$ 이었고 기름의 경우에는 $3.4 \sim 630$ 이었다. Fig. 7 8은 물과 기름에 대한 실험 결과이며 Graetz의 수에 대하여 Nusselt 수와 $\mathrm{Ra} / \mathrm{Gz}$ 수로 나타낸 것이다. 두 개의 그림에서 오른쪽으로 갈수록 즉, $\mathrm{Ra} / \mathrm{Gz}$ 수의 비가 증가하여 자연대류의 영 향이 커지면서 열전달이 단조 증가하는 것을 볼 수 있다.

\section{2-7. 문헌별 내용 요약 및 데이터 추출}

Table 1 2는 원 문헌의 내용을 요약한 것이다. 유 동의 영역지도를 재구성하기 위하여 그래프로부터 데 이터를 추출하고 상관식을 정리하였다.

Table 3은 유동영역지도를 재구성하기 위한 열전 달상관식이다. Fig. 1의 지도에서 큰 틀을 구성하는 강제대류와 혼합대류, 자연대류와 혼합대류를 구분하 는 두 개의 열전달상관식은 Martinelli와 Boelter의 이론이 근원이지만 Eckert와 Diaguila ${ }^{(11)}$ 가 제시한 식 (8)과 (9)를 활용하였다. 천이영역에 해당하는 세 개 의 실선에 대해서는 Hallman의 문헌에서만 천이영역 의 상관식이 제시되어 있었고 Brown과 Hanratty문헌

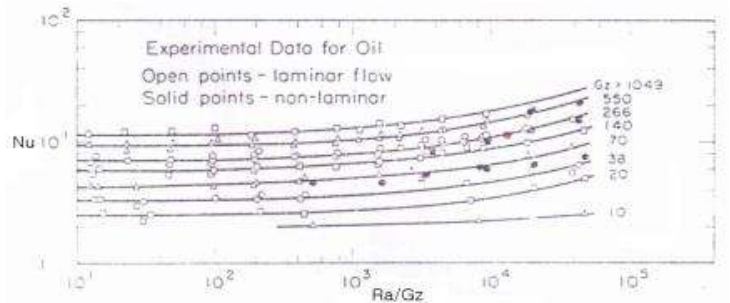

Fig. 7. $\mathrm{Nu}$ vs. $\mathrm{Ra} / \mathrm{Gz}$ for constant Graetz number (Oil).

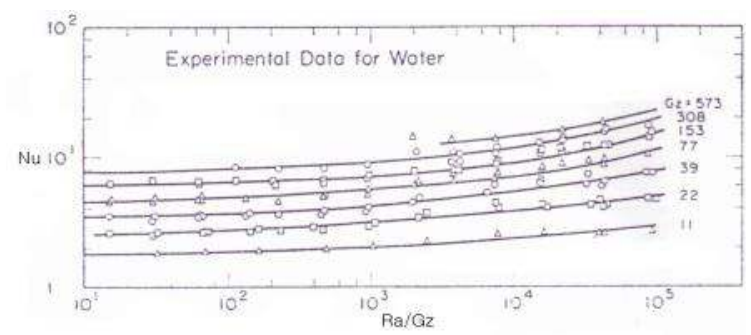

Fig. 8. Nusselt number vs. $\mathrm{Ra} / \mathrm{Gz}$ for constant Graetz number (Water).

에는 상관식을 찾아볼 수 없었다. 이미 잘 알려진 바 와 같이 유동영역지도의 가로축은 $\mathrm{GrPr} /\left(\mathrm{D}_{\mathrm{i}} / \mathrm{L}\right)$ 수, 그 리고 세로축이 Reynolds 수로 되어있다. 유동영역지 도를 재구성하기 위해서는 무차원수의 값들을 알아내 는 것이 중요하다. 그러나 조사된 대부분의 문헌들은 Grashof 수와 Reynolds 수의 범위가 모호하게 기록 되어 있고 연구결과의 그래프들도 축이 Reynolds 수 가 아닌 Nusselt 수로 되어있어서 필요한 데이터를 찾기가 쉽지 않다. 따라서 원 문헌에 제시된 그래프 의 눈금을 읽고 찾아내는 수밖에 없었고 자료가 확보 되지 않은 Brown 및 Hanratty의 상관식과 Brwon, Petuchov 그리고 Metais의 데이터는 Fig. 1 의 유동영 역지도에서 추출하여 지도를 재구성하는데 활용하였 다.

\section{3. 유동영역지도 재구성 및 유효성 검토}

Fig. 9는 조사된 상관식과 추출한 데이터를 이용하 여 독립적으로 재구성한 지도이다. 기존의 유동영역 지도와 비교해보면 유사한 형태를 취하는 것처럼 보 이지만 상당한 면에서 다른 점들을 찾을 수 있고 기 존의 유동영역지도에 나타나 있는 문제점들에 대해서 도 생각해 볼 수 있다.

Fig. 9에서 혼합대류영역을 나타내는 두 개의 실선 이 오른쪽 상단으로 가면서 휘어지다가 평평해지는 패턴에 대해서는 이미지를 연상시킬 경우에는 생각해 
Table 1. Information in literatures.

\begin{tabular}{|c|c|c|c|}
\hline & Brown & Eckert et al. & Kemeny \& Somers \\
\hline Boundary condition & UWT & $\mathrm{UHF}$ & UWT \\
\hline Flow & Turbulent & Laminar & Laminar to turbulent \\
\hline Direction & $\begin{array}{c}\text { Buoyancy-aided, } \\
\text { Buoyancy-opposed, }\end{array}$ & Buoyancy-aided & $\begin{array}{l}\text { Buoyancy-aided, } \\
\text { Buoyancy-opposed, }\end{array}$ \\
\hline Prandtl & Air : 0.7 & $\begin{array}{l}\text { Water : } 3 \sim 6 \\
\text { Oil : } 80 \sim 170\end{array}$ & Water : $2 \sim 5$ \\
\hline Ranges & $\begin{array}{c}36 \times 10^{3} \leq \operatorname{Re}_{\mathrm{D}} \leq 37.7 \times 10^{4} \\
50 \times 10^{3} \leq \mathrm{Re}_{\mathrm{x}} \leq 70 \times 10^{4} \\
10^{9} \leq \mathrm{Gr}_{\mathrm{x}} \leq 10^{13}\end{array}$ & $\begin{array}{c}\text { Water : } 61 \leq \mathrm{Re}_{\mathrm{D}} \leq 6800 \\
\text { Oil : } 3.4 \leq \mathrm{Re}_{\mathrm{D}} \leq 630 \\
10^{2} \leq \mathrm{Gr}_{\mathrm{D}} \leq 10^{5}\end{array}$ & $\begin{array}{c}6 \times 10^{6} \leq \mathrm{Gr}_{\mathrm{D}} \leq 10^{8} \\
1450 \leq \mathrm{Re}_{\mathrm{D}} \leq 15000\end{array}$ \\
\hline Length scale & Distance from heated wall (x) & Pipe diameter $(\mathrm{D})$ & Pipe diameter (D) \\
\hline $\mathrm{L}(\mathrm{m})$ & 3.05 & 2.44 & 1 \\
\hline $\mathrm{D}(\mathrm{m})$ & 0.61 & $\begin{array}{c}0.00635,0.0127,0.0254 \\
0.0381\end{array}$ & 0.05 \\
\hline $\mathrm{L} / \mathrm{D}$ & 5 & $9.7 \sim 320$ & 20 \\
\hline
\end{tabular}

Table 2. Information in literatures.

\begin{tabular}{c|c|c|c}
\hline & Hanratty et al. & Hallman & Martinelli \& Boelter \\
\hline \hline Boundary condition & UHF, UWT & UHF & Laminar \\
\hline Flow & $\begin{array}{c}\text { Transition, Laminar to } \\
\text { turbulent }\end{array}$ & $\begin{array}{c}\text { Transition, Laminar to } \\
\text { turbulent }\end{array}$ & Buoyancy-aided \\
\hline Direction & $\begin{array}{c}\text { Buoyancy-aided, } \\
\text { Buoyancy-opposed, }\end{array}$ & $\begin{array}{c}\text { Buoyancy-aided, } \\
\text { Buoyancy-opposed, }\end{array}$ & - \\
\hline Prandtl & Water $: 5.52$ & Water & - \\
\hline Ranges & $3 \times 10^{3} \leq \mathrm{Gr}_{\mathrm{D}} \leq 10^{4}$ & $10^{4} \leq \mathrm{Gr}_{\mathrm{D}} \leq 4.5 \times 10^{6}$ & $140 \leq \mathrm{Re}_{\mathrm{D}} \leq 4300$ \\
\hline Length scale & $40 \leq \mathrm{Re}_{\mathrm{D}} \leq 350$ & Pipe diameter (D) & Pipe diameter (D) \\
\hline $\mathrm{L}$ & Pipe diameter (D) & 0.92 & - \\
\hline $\mathrm{D}_{\mathrm{i}}$ & 2.52 & 0.008 & - \\
\hline $\mathrm{L} / \mathrm{D}_{\mathrm{i}}$ & 0.022 & 115 & - \\
\hline
\end{tabular}

Table 3. Convective heat transfer correlations for reconstructing flow regime map.

\begin{tabular}{c|cc}
\hline Authors & Correlations \\
\hline \hline Eckert \& Diaguila & (Between Forced and Mixed) $R e_{D}=19.64\left(G r_{D}\right)^{0.35}$ & $(8)$ \\
& (Between Natural and Mixed) $R e_{D}=7.39\left(G r_{D}\right)^{0.35}$ \\
\hline Hallman & (Transition laminar-turbulent) $R a_{D}=9470\left(\frac{R e P r}{2 x / D}\right)^{1.83}$ & (7) \\
\hline
\end{tabular}

볼 수 있지만 재구성한 지도에서는 직선으로 나타났 다. 또한, 천이영역에서 가로방향의 굵은 선에 대해서 는 어떠한 정보도 문헌에서 찾아 볼 수 없다. 데이터 포인트의 수가 많은 Fig. 9와 달리 기존의 유동영역 지도에는 몇 안 되는 데이터만 들어가 있다. 한 예로,
Watzinger와 Johnson의 결과인 그림 2와 Kemeny와 Somers의 결과인 그림 7과 8을 살펴보면 상당히 많 은 수의 데이터가 들어있지만 재구성한 그림에는 그 렇지가 않다. 실제로 Metais와 Eckert의 1964년 유동 영역지도의 문헌을 살펴보면 어떠한 방법에 의해 이 


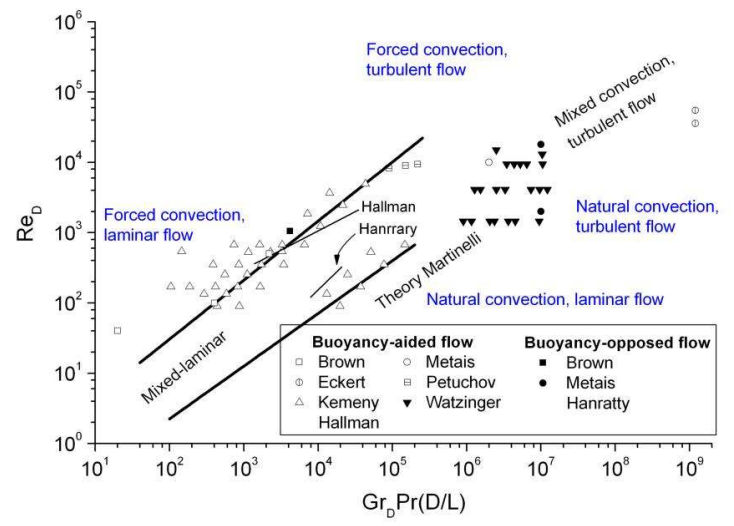

Fig. 9. Redrawn flow regime map on mixed convection in vertical cylinders.

러한 지도가 만들어졌는지에 대한 구체적인 설명은 언급되어 있지 않다. 다만, 지도의 가로축과 세로축에 대한 설명, Grashof 수의 길이 척도로 관의 지름이 사용되었다는 것 등의 개략적인 설명뿐이다. 그리고 지도를 구성하고 있는 문헌들은 1964년보다 이전에 수행되었던 연구결과들이며, 순부력 유동과 역부력 유동의 결과가 하나의 유동영역지도로 그려졌다는 것 이 내용의 전부이다.

자연대류의 부력은 가열벽면의 높이에 3승에 비례 한다는 것이 일반적으로 알려진 사실이다(12). 그러나 지도를 구성하고 있는 문헌들의 대부분이 Grashof 수 의 길이척도로 관의 지름이 사용되었으며 유동영역지 도의 가로축도 마찬가지다. 또한, Metais와 Eckert의 유동영역지도에 대한 연구는 Grashof 수 $10^{9}$ 까지와 Reynolds 수 $10^{4}$ 이하에서만 수행되었다.

\section{4. 결 론}

본 연구는 기존 문헌조사를 통하여 Metais와 Eckert가 제시한 기존의 유동영역지도에 대해 검토를 하였다. 지도를 구성하는 원 문헌들을 수집하여 내용 을 정리하였다. 이로부터 조사된 자료를 활용하여 지 도를 재구성하고 기존의 지도와 비교하였다. 검토결 과, 지도를 구성하는 문헌에는 상당히 많은 양의 원 래 데이터가 있었는데 일부만이 선택적으로 사용되었 다. 혼합대류 영역을 나타내는 선이 곡선이 아니라 직선으로 나타났으며 문헌에는 곡선이 어떻게 만들어 졌는지에 대해서는 언급되지 않았다. 또한, 천이영역 을 나타내는 영역은 재구성한 지도에는 나타나지 않
았다. 결과적으로 기존의 유동영역지도는 많은 데이 터 가운데 일부를 선택적 사용, 인용한 연구의 제한 적 사용, 지도구성에 대한 부족한 언급 등 근거가 확 실하지 않았으며 불확실도 분석을 통한 정보를 제공 하고 있지 않기 때문에 그것에 대한 신뢰성 또한 부 족하다. Grashof 수가 가열벽 높이의 3승에 비례함에 도 불구하고 특성길이로 관의 직경을 사용했기 때문 에 일반적으로 사용되기가 어렵다. 또한, 순부력 유동 과 역부력 유동을 구분하지 않고 하나의 그림으로 그 려졌으며, Grashof 수 $10^{9}$ 까지와 Reynolds 수 $10^{4}$ 이 하에서만 수행되어 그 이상의 범위에 대해서는 이 지 도를 적용할 수가 없다. Metais와 Eckert의 연구 이 후, 상당한 연구가 수행되었음에도 불구하고 유동영 역을 구분하는 방법으로 기존의 유동영역지도가 지금 까지 활용되고 있었다.

\section{기호설명}

$\mathrm{D}_{\mathrm{i}}$

$\mathrm{Gr}_{\mathrm{D}}$

: 수직 원형관의 내경 $(\mathrm{m})$

$\mathrm{Gr}_{\mathrm{H}}$

: Grashof 수 $\left(\mathrm{g} \beta \triangle \mathrm{TD}^{3} / \mathrm{v}^{2}\right)$

$\mathrm{G}_{\mathrm{z}}$

: Grashof 수 $\left(\mathrm{g} \beta \triangle \mathrm{TH}^{3} / \mathrm{v}^{2}\right)$

$\mathrm{h}_{\mathrm{h}}$

: Graetz 수 $\left(\operatorname{RePr}\left(\mathrm{D}_{\mathrm{i}} / \mathrm{L}\right)\right)$

$\mathrm{h}_{\mathrm{h}} \quad$ : 대류열전달계수 $\left(\mathrm{W} / \mathrm{m}^{2} \cdot \mathrm{K}\right)$

$k \quad$ : 전도계수 $(\mathrm{W} / \mathrm{m} \cdot \mathrm{K})$

$\mathrm{L}$ or $\mathrm{H}$ : 수직 원형관 높이

$\mathrm{Nu}_{\mathrm{D}} \quad$ : Nusselt 수 $\left(\mathrm{hh}_{\mathrm{Di}} / \mathrm{k}\right)$

$\mathrm{Nu}_{\mathrm{H}} \quad:$ Nusselt 수 $\left(\mathrm{hh}_{\mathrm{H}} / \mathrm{k}\right)$

Pr : Prandtl 수 $(\nu / \alpha)$

$\mathrm{Ra}_{\mathrm{Di}} \quad:$ Rayleigh 수 $\left(\mathrm{Gr}_{\mathrm{Di}} \mathrm{Pr}\right)$

$\mathrm{Ra}_{\mathrm{H}} \quad:$ Rayleigh 수 $(\mathrm{GrHPr})$

$\operatorname{Re} \quad:$ Reynoles 수 $\left(\mathrm{VD}_{\mathrm{i}} / \mathrm{v}\right)$

V

: Mean velocity $(\mathrm{m} / \mathrm{s})$

\section{Greek symbols}

$$
\begin{array}{ll}
\alpha & : \text { 열확산계수 }\left(\mathrm{m}^{2} / \mathrm{s}\right) \\
\beta & : \text { 부피팽창계수 }\left(\mathrm{m}^{3} / \mathrm{K}\right) \\
\nu & : \text { 동점성계수 }\left(\mathrm{m}^{2} / \mathrm{s}\right) \\
\mu & : \text { 점성계수 }(\mathrm{kg} / \mathrm{ms}) \\
\rho & : \text { 밀도 }\left(\mathrm{kg} / \mathrm{m}^{3}\right)
\end{array}
$$




\section{References}

1. Incropera, F.P., Dewitt, D.P., 2003, Fundamentals of Heat and Mass Transfer, 5th ed., John Wiley \& Sons, New York.

2. Bejan, A., 1994, Convective Heat Transfer, 2nd ed., John Wiley \& Sons, INC, New York

3. Ko B.J., Lee W.J., Chung B.J., Turbulent mixed convection heat transfer experiments in a vertical cylinder using analogy concept, Nuclear Engineering Design, 2010, 240, 3967-3973.

4. Metais. B., Eckert, E. R. G., Forced, mixed, and free convection regimes, Journal of Heat Transfer, 1964, 86, 295-296.

5. Watzinger, A., Johnson, D. G., Wirmeiibertragung von Wasser an Rohrwand bei senkrechter Str6mung im Obergangs-gebiet zwischen laminarer und turbulenter StrSmung. Forschung auf dem Gebiete des Ingenierwesens, 1939, 10, 182-196.

6. Martinelli, R. C., Boelter, L. M. K., An analytical prediction of superimposed free and forced viscous convection in a vertical pipe, Univ. Calif. Publ. in Eng, 1942, 5(2), 23-58.

7. Eckert, E. R. G., Diaguila, A. J., Convective heat transfer for mixed free and forced flow through tubes, Trans. ASME, 1954, 76, 497-504.

8. Hanratty, T. J., Rosen, E. M., Kabel, R. L., Effect of heat transfer on flow field at low Reynolds numbers in vertical tubes. Industrial and Engineering Chemistry, 1958, 50, 815-820.

9. Hallman, T. M., Combined forced and free laminar heat transfer in vertical tubes with uniform internal heat generation. Trans. ASME, 1956, 78, 1831-1841.

10. Kemeny, G. A., Somers, E. V., Combined free and forced convection flow in vertical circular tubes-Experiments with water and oil, Trans. ASME C, J. Heat Transfer, 1962, 84, 339-346.
11. Eckert, E. R. G., Diaguila, A. J., Convective heat transfer for mixed free and forced flow through tubes, Trans. ASME, 1954, 76, 497-504.

12. Kang, G.U., Chung, B.J., The experimental study on transition criteria of natural convection inside a vertical pipe, International Communication of Heat and Mass transfer, 2011, 37(8), 1057-1063. 